University of Nebraska - Lincoln

DigitalCommons@University of Nebraska - Lincoln

$3-2003$

\title{
Subgrouping Poor Readers on the Basis of Individual Differences in Reading-Related Abilities
}

Hugh W. Catts

University of Kansas

Tiffany Hogan

University of Nebraska - Lincoln, thogan2@unl.edu

Marc E. Fey

University of Kansas Medical Center

Follow this and additional works at: https://digitalcommons.unl.edu/specedfacpub

Part of the Special Education and Teaching Commons

Catts, Hugh W.; Hogan, Tiffany; and Fey, Marc E., "Subgrouping Poor Readers on the Basis of Individual Differences in Reading-Related Abilities" (2003). Special Education and Communication Disorders Faculty Publications. 18.

https://digitalcommons.unl.edu/specedfacpub/18

This Article is brought to you for free and open access by the Department of Special Education and Communication Disorders at DigitalCommons@University of Nebraska - Lincoln. It has been accepted for inclusion in Special Education and Communication Disorders Faculty Publications by an authorized administrator of DigitalCommons@University of Nebraska - Lincoln. 


\title{
Subgrouping Poor Readers on the Basis of Individual Differences in Reading-Related Abilities
}

\author{
Hugh W. Catts, Tiffany P. Hogan, and Marc E. Fey
}

\begin{abstract}
The present study investigated the use of the Reading Component Model to subgroup poor readers. A large sample of poor readers was identified in second grade and subgrouped on the basis of relative strengths and weaknesses in word recognition and listening comprehension. Although homogeneous subgroups were not identified, poor readers could be classified into four subgroups that differed significantly in reading-related abilities. Further analyses showed that poor readers' strengths and weaknesses in listening comprehension, and to a lesser extent in word recognition, were foreshadowed by their abilities on related kindergarten measures. Follow-up testing in the fourth grade indicated that poor readers' individual differences in word recognition and listening comprehension were consistent and that subgroups were moderately stable. The implications of these results for the assessment and remediation of reading disabilities are discussed.
\end{abstract}

$\mathrm{T}$ he use of IQ-achievement discrepancy to classify poor readers has played a central role in the field of reading and learning disabilities. In this approach, poor readers are subgrouped into those displaying a discrepancy between IQ and reading achievement scores and those who do not show such a discrepancy. The former have often been referred to as children with dyslexia or specific reading disability, and the latter are frequently labeled slow learners or garden-variety poor readers. Whereas classification based on IQ-achievement discrepancy has been widespread, its validity and utility have been challenged, especially in recent years (Aaron, 1991, 1997; Fletcher et al., 1998; Siegel, 1989; Stanovich, 1991).

Challengers have addressed a number of critical issues. These include a lack of support for a strong and unidirectional relationship between IQ and reading achievement (Siegel, 1989; Stanovich, 1991). Critics also have noted the lack of evidence of qualitative differences between IQ-achievement discrepancy subgroups on reading-related factors (Ellis, McDougall, \& Monk, 1996; Fletcher et al., 1994; Flowers, Meyer, Lovato, Wood, \& Felton, 2001; Pennington, Gilger, Olson, \& DeFries, 1992; Stanovich \& Siegel, 1994). Another major issue of particular relevance to the present investigation has been the inability of the IQachievement discrepancy approach to provide guidance for intervention (Aaron, 1991; Forness, Sinclair, \& Guthrie, 1983). As applied, the IQ diagnostic model does not identify individual subgroup differences that can be used to plan specific intervention goals or activities. Rather, in this approach, poor readers are subgrouped in such a way that those who show an IQ-achievement discrepancy most often qualify for special education programs, whereas those without a discrepancy do not. Such a procedure is based on the belief that the low IQs of the latter group place a limit on their reading achievement. Thus, rather than prescribing specific reading intervention, the IQ-achievement discrepancy model actually excludes many children from such intervention.

Others have proposed an alternative method for subgrouping poor readers that is more prescriptive in nature (Aaron, 1997; Aaron, Joshi, \& Williams, 1999; Catts \& Kamhi, 1999; Savage, 2001). This approach focuses on individual differences among poor readers in critical components of reading. As such, it has been referred to by Aaron (1997) as the Reading Component Model. This model, as presented here, is based largely on the Simple View of Reading proposed by Gough and Tunmer (1986) and Hoover and Gough (1990). According to this view, reading comprehension is composed of two basic components: word recognition and linguistic comprehension. Simply stated, the word recognition component translates print into a linguistic form, and the comprehension component makes sense of this linguistic information. Because the latter component is similar to that involved in spoken language comprehension and can be measured independently of reading, it is sometimes referred to as listening comprehension. 
In a test of this view, Hoover and Gough (1990) showed that measures of word recognition and listening comprehension accounted for a large proportion of the variance in reading comprehension among bilingual children in Grades 1 through 4. Others have also provided support for this model of reading comprehension (Carver, 1998; Curtis, 1980; de Jong \& van der Leij, 2002; Jackson \& McClelland, 1979; Palmer, McCleod, Hunt, \& Davidson, 1985).

As applied to reading disabilities, the Reading Component Model predicts that poor readers may differ across the dimensions of word recognition and listening comprehension (Aaron, 1997; Catts \& Kamhi, 1999; Gough \& Tunmer, 1986). At least three different subgroups of poor readers may be identified:

1. poor readers with word recognition problems only,

2. poor readers with listening comprehension problems only, and

3. poor readers with a combination of these problems.

Furthermore, each of these subgroups of poor readers may differ in the causal basis of their reading difficulties and, therefore, may require a different set of intervention strategies.

Research has provided some initial support for the classification of poor readers based on the Reading Component Model. For example, considerable attention has been devoted to poor readers whose primary problems are in the area of word recognition (Bruck, 1988; Rack, Snowling, \& Olson, 1992; Torgesen, 1999). These children have typically met the IQ-achievement discrepancy criterion and have often been referred to as having dyslexia. Due to the heavy emphasis on this subgroup, it might be assumed that children with primary problems in word recognition represent a large proportion of poor readers.

Children who have problems primarily in listening comprehension have also come to the attention of researchers and practitioners (Nation,
1999; Stothard, 1994; Stothard \& Hulme, 1992). This subgroup of children has most often been referred to as having hyperlexia (Aaron, Frantz, \& Manges, 1990; Aram, Rose, \& Horwitz, 1984). Initially, this term was reserved for children with precocious and exceptional word decoding skills in the face of limited comprehension and cognitive abilities, a profile occasionally associated with autism (Elliot \& Needleman, 1976; Silberberg \& Silberberg, 1967). However, more recently, hyperlexia has been used to characterize children with poor language comprehension and relatively good word recognition (Gough \& Tunmer, 1986). It has been estimated that these children represent approximately $15 \%$ of poor readers (Aaron, 1997; Nation, 1999).

According to the Reading Component Model, a third subgroup of poor readers have problems in both word recognition and listening comprehension. Because these children perform poorly on verbally loaded IQ tests, they frequently have been labeled slow learners or garden-variety poor readers. Some, on the other hand, have referred to these children as having language-learning disabilities (LLD) in order to highlight their language deficits (Catts \& Kamhi, 1999; Lombardino, Leonard, \& Eckert, 2001). It is only recently, however, that these children have been the focus of research investigations (Goulandris, Snowling, \& Walker, 2000; Heath, Hogben, \& Clark, 1999; Joanisse, Mannis, Keating, \& Seidenberg, 2000; Leonard, 2001). Therefore, little is known about the prevalence or nature of this subgroup of poor readers.

Whereas each of the above subgroups has been identified in research, few studies have directly applied the Reading Component Model to identify these subgroups in a single study. In the one exception of which we are aware, Aaron et al. (1999) employed a variant of this model to classify poor readers from three different samples. Their results provided evidence for each of the aforementioned subgroups and showed that their prevalence varied depending on the characteristics of the sample (e.g., learning disabled vs. Title 1 poor readers). However, because their poor reader samples were small $(n<$ $25)$, conclusions regarding the validity and usefulness of this classification approach were limited.

The purpose of the present study, therefore, was to further investigate the applicability of the Reading Component Model for subgrouping poor readers. We identified a sample of 183 poor readers in second grade and subgrouped them according to their word recognition and listening comprehension abilities. Moreover, we examined kindergarten and fourthgrade reading-related abilities in these subgroups to explore the development and the stability of these abilities as they relate to this classification system. We expected that poor readers would differ in their word recognition and listening comprehension abilities and that their performance on these two parameters would be independent. We also predicted that the strengths and weaknesses of the Reading Component subgroups on word recognition and listening comprehension would be foreshadowed by their kindergarten performances on related variables. Finally, we expected that subgroups would show moderate stability in their word recognition and listening comprehension abilities through the fourth grade.

\section{Method}

\section{Participants}

The participants in this investigation were identified in a longitudinal study of language impairments in children (Tomblin, 1995). As part of the longitudinal investigation, 604 children were tested in kindergarten and followed through fourth grade. By design, many of these children had language impairments in kindergarten (see Catts, Fey, Zhang, \& Tomblin [1999] for a further description of the original sample). In second grade, the children's reading achievement was assessed. On the basis of this assessment, 183 children were identified as poor readers. 
Poor readers were defined as those who performed at least 1 SD below the mean of a composite measure of reading comprehension (described later). This cutoff level is similar to that used by other researchers in the field of reading disabilities (e.g., Hurford, Schauf, Bunce, Blaich, \& Moore, 1994; Meyer, Wood, Hart, \& Felton, 1998). It also represents a compromise criterion level when compared to that found in more liberal definitions (25th percentile; Fletcher et al., 1994; Stanovich \& Siegel, 1994) or in more conservative definitions of reading disabilities (1.5 SD; Badian, McAnulty, Duffy, \& Als, 1990).

Given the criterion we used for reading disability, the proportion of children we identified as poor readers was higher than would be expected from a representative sample (30\% vs. 16\%). However, this higher prevalence rate was consistent with the high incidence of early language impairments in the original sample of children. Such a sample composition could have biased our results, especially because we were interested in subgroups that differed in language abilities. To ensure that our results were more representative of poor readers from the general population, we employed a weighting procedure in all data analyses (described in the results section).

Finally all poor readers had normal hearing and no history of significant emotional or neurological disorders. Whereas none of the poor readers had been identified as having mental retardation at the beginning of the study, some did perform in the low-average to below-average range of intelligence on standardized IQ tests.

\section{Measures}

The focal point of testing in this investigation was the second grade. At this grade, measures were administered to identify and subgroup poor readers. All children, however, were also tested in kindergarten and fourth grade. The specific measures employed at each grade level are described in the following sections.
Kindergarten. In kindergarten, the participants completed a battery of tests including measures of listening comprehension, phonological processing, letter identification, and nonverbal intelligence.

Listening comprehension. Listening comprehension was measured by a combination of receptive language measures of vocabulary, grammar, and narration. These included the Picture Vocabulary and Grammatical Understanding subtests from the Test of Language Development--2: Primary (TOLD-2:P; Newcomer \& Hammill, 1988). Narrative abilities were assessed by a story comprehension task developed by Culatta, Page, and Ellis (1983). Children's raw scores on each of these measures were converted to $z$ scores based on the means and standard deviations of a local normative sample of 1,475 kindergarten children (see Tomblin et al., 1997). These $z$ scores were subsequently employed to create composite $z$ scores for listening comprehension. (For further details concerning this assessment and other testing, see Catts, Fey, Zhang, \& Tomblin, 1999, 2001.)

Phonological processing. Measures of phonological awareness and rapid naming were also administered in kindergarten. The phonological awareness task was a measure of syllable/ phoneme deletion (Catts et al., 2001) and was an adaptation of Rosner's Auditory Analysis Test (Rosner \& Simon, 1971). In this task, participants were required to delete a syllable or, in some cases, a phoneme of a word and say the remaining sound sequence.

The Rapid Automatized Naming of Animals task (Catts et al., 2001) was administered as a measure of rapid naming. In this task, participants rapidly named a series of 24 colored animals (e.g., red pig, blue cow, black horse) presented on an $81 / 2 \times 11$-inch chart. The total time (in seconds) required to name all stimulus items served as the index of performance.

Letter identification. Participants also completed the Letter Identification subtest of the Woodcock Reading Mastery Tests-Revised (WRMT-R; Woodcock, 1987). Because the letters in this test are shown in various type- faces, it may be sensitive to individual differences in literacy experience as well as letter-name knowledge.

Nonverbal intelligence. The Block Design and Picture Completion subtests of the Wechsler Preschool and Primary Scale of Intelligence-Revised (WPPSI-R; Wechsler, 1989) were administered as a shortened version of the Performance scale (Bishop \& Adams, 1990; LoBello, 1991).

Second Grade. In addition to the variables assessed in kindergarten, children's word recognition, reading comprehension, and reading experience were measured in second grade.

Listening comprehension. Because of potential ceiling effects, the language tests used in kindergarten to measure listening comprehension could not be employed in second grade. Therefore, a new combination of receptive vocabulary, grammar, and narration tests was administered. This included the Peabody Picture Vocabulary Test--Revised (Dunn \& Dunn, 1981) and the Sentence Structure, Concepts and Directions, and Listening to Paragraphs subtests of the Clinical Evaluation of Language Fundamentals--3 (CELF-3; Semel, Wiig, \& Secord, 1995). Children's raw scores on each of these language measures were converted to $z$ scores based on the weighted means and standard deviations of the 604 children participating in the follow-up investigation (see Tomblin et al., 1997). These $z$ scores were subsequently employed to create a composite $z$ score for listening comprehension.

Phonological processing. The syllable/phoneme deletion task and rapid naming measure used in kindergarten were readministered in second grade.

Word recognition. To assess word recognition, the Word Identification and Word Attack subtests of the WRMT-R were administered to each of the participants. Raw scores were converted to standard scores based on test norms. These standard scores were converted to weighted $z$ scores to form a composite score for word recognition. 
Reading comprehension. Participants completed three tests of reading comprehension. These included the Passage Comprehension subtest of the WRMT-R, the comprehension component of the Gray Oral Reading Test-3, (Wiederholt \& Bryant, 1992), and the Reading Comprehension subtest of the Diagnostic Achievement Battery-2 (Newcomer, 1990). A procedure similar to that described for word recognition was used to convert raw scores to standard scores and to form a composite measure of reading comprehension.

Reading experience. Children's reading/literacy experience was measured indirectly by the use of the Title Recognition Questionnaire. This instrument was an adaptation of a similar task developed by Cunningham and Stanovich (1990; see also Stanovich \& West, 1989). Children were shown a printed list of 34 book titles. This included 26 titles of books commonly read by or to young children and 8 foils that were not book titles. The participants were required to read the list and select which were "real titles" of children's books. Participants received 1 point for each correct selection and were penalized 1 point for each incorrect choice of a foil (total possible score $=26$ ).

Intelligence. Participants also completed the five standard subtests of the Performance scale of the Wechsler Intelligence Scale for Children-III (Wechsler, 1991). Scores on these subtests were converted to a composite measure using the standard test procedures.

Fourth Grade. Measures of word recognition, listening comprehension, and reading comprehension given in the second grade were readministered in the fourth grade. The one exception was the Sentence Structure subtest of the CELF-3, which was no longer age appropriate and, therefore, was not included as part of the measure of listening comprehension.

\section{Procedure}

Testing was conducted by trained examiners with undergraduate or graduate degrees in speech-language sciences/pathology or education. Testing took place in specially designed vans parked at the participants' schools or homes and was completed during two 2-hour sessions at each grade level.

\section{Results}

\section{Weighting Scores}

As noted earlier, the sample from which the poor readers were drawn had a higher prevalence of children with language impairments than the general population. To improve the representativeness of our data, we used weighted scores that took into consideration the prevalence rates for language impairments and other characteristics in the general population. The sample of children from which we identified our poor readers was itself a subsample of more than 7,000 children who took part in an epidemiologic study of language impairments in kindergarten children (Tomblin et al., 1997). Data from this epidemiologic study provided us with an estimate of the prevalence rates of children with or without language impairments or nonverbal cognitive deficits, as well as expected rates of boys and girls in each of these categories. Based on these data, we determined how likely it was that a participant with his or her gender, language, and nonverbal IQ profile would have been part of the representative sample seen in the epidemiologic study and weighted his or her scores accordingly. For example, the epidemiologic study estimated that boys with a language impairment and average nonverbal IQ composed $3.9 \%$ of the general population. In our original sample $(N=604)$, however, these children composed $12.1 \%$. To ensure that participants from this group did not contribute disproportionately to our results, their scores were adjusted by a constant that was equal to the expected prevalence of these children $(3.9 \%)$ divided by their actual prevalence in our sample $(12.1 \%$; constant $=.322)$. A similar procedure was used to weight the scores of other participants based on their specific characteristics. (For further details concerning the weighting procedure and evidence of its effectiveness, see Catts et al., 1999.)

\section{Reading Component Model}

In the first set of analyses, we investigated the ability of the Reading Component Model to subgroup poor readers. If the model is to be useful in classification, a sample of poor readers should exhibit a broad range of performance on measures of word recognition and listening comprehension. More important, performance in these dimensions should be independent or, at best, only weakly correlated (e.g., $r<.25$ ).

To test this hypothesis, we examined the relationship between second-grade composite measures of word recognition and listening comprehension. The Pearson productmoment correlation coefficient between these measures was .16 ( $p<$ .05). Although this correlation is statistically significant, it indicates that the performance on one of the target components of the Reading Component Model accounts for less than $3 \%$ of the variance in the other component. Thus, as predicted, the components of this model proved to be relatively independent within our sample of poor readers.

\section{Subgroups of Poor Readers}

Given the above finding, poor readers could be distributed in one of two ways (Ellis, 1985). First, poor readers might cluster into subgroups that differ qualitatively from each other in their distinct pattern of strengths and weaknesses in word recognition and listening comprehension. In other words, poor readers could form clusters, or "galaxies," in the two-dimensional space representing these abilities. Second, poor readers might not form homogeneous subgroups. Rather, their reading-related abilities could be distributed continuously throughout the two-dimensional space of word recognition and listening comprehension, 
suggesting differences that are more quantitative than qualitative.

The data displayed in Figure 1 conform most closely to the second possible distribution (see Note 1). This figure illustrates the broad ranges of performance on word recognition and listening comprehension measures found among the poor readers in our sample. It is noteworthy, however, that few poor readers exceeded or even approached the average score (i.e., $z$ score $=0$ ) for their age on either measure. More important, the scatter plot in Figure 1 shows that there are no clear breaks or divisions separating poor readers and, thus, provides no evidence of homogeneous clusters.

Although distinct subgroups were not observed, poor readers did show considerable individual differences in their strengths and weaknesses in word recognition and listening comprehension. This variability can be captured by imposing boundaries to identify subgroups. Of course, the choice of boundary lines or cutoff values for defining a deficit will influence the estimate of the prevalence of the corresponding subgroups. For the present study, we chose a rather standard cutoff value for poor performance in word recognition or listening comprehension as a $z$ score of less than -1 . This was also consistent with the reading comprehension cutoff score we used to identify poor readers.

According to this scheme, poor readers with good or at least adequate listening comprehension and poor word recognition were classified as having dyslexia (see Figure 1). Those with poor performance in both word recognition and listening comprehension were classified as having language-learning disabilities (LLD). Poor readers who showed good or at least adequate word recognition but poor listening comprehension were defined as having hyperlexia (see Note 2). Finally, a nonspecified subgroup that was composed of poor readers with adequate performance in both word recognition and listening comprehension was identified.

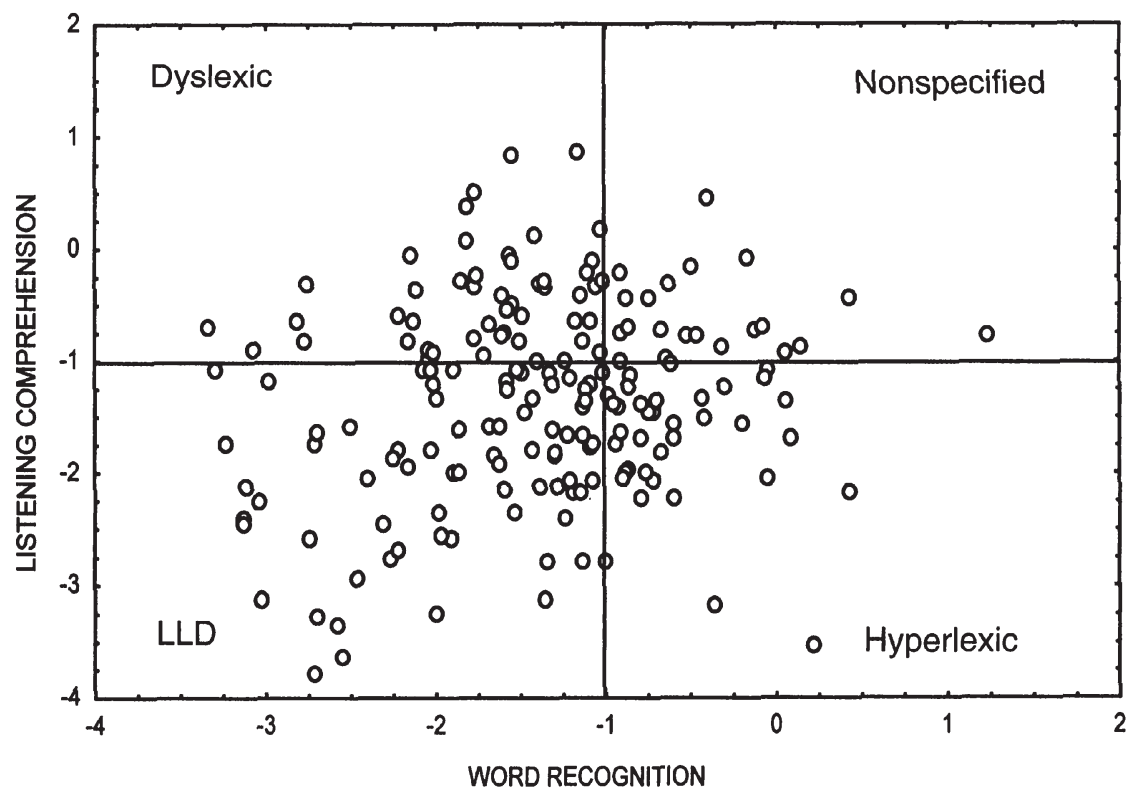

Figure 1. Scatter plot representing listening comprehension and word recognition scores of poor readers as delineated into four subgroups.

Figure 2 displays the weighted prevalence of poor readers in each of the above subgroups. These data indicate that $35.5 \%$ of poor readers in second grade could be classified as having dyslexia, $35.7 \%$ as having LLD, $15.4 \%$ as having hyperlexia, and $13.4 \%$ as having a nonspecified reading problem (see Note 3 ). Table 1 shows the means and standard deviations of each subgroup on various measures completed in second grade. For ease of interpretation of the data in this and other tables, $z$ scores have been converted to standard scores with a mean of 100 and a standard deviation of 15 . As expected, given the way subgroups were defined, ANOVA, $F(3,179)$ $=70.7, p<.001$, and follow-up LSD comparisons $(p<.001)$ showed that poor readers in the dyslexic and LLD subgroups had significantly lower word recognition abilities than did those in the hyperlexic and nonspecified subgroups. Similarly, ANOVA, $F(3,179)=105.1, p<.001$, and follow-up tests $(p<.001)$ indicated that poor readers in the LLD and hyperlexic subgroups had significantly lower listening comprehension abilities than did those in the dyslexic and nonspecified subgroups.
Moreover, subgroups differed significantly in reading comprehension, $F(3,179)=13.0, p<.001$, and nonverbal IQ, $F(3,179)=19.4, p<.001$. In the case of reading comprehension, children in the LLD subgroup scored significantly lower than those in the dyslexic subgroup $(p<.01)$, and children in both of the latter subgroups scored significantly lower than those in the hyperlexic and nonspecified subgroups $(p<.001)$. Finally, children in the dyslexic and nonspecified subgroups had significantly higher nonverbal IQs than those in the LLD and hyperlexic categories ( $p$ $<$.005).

\section{Subgroup Precursors}

We predicted that the strengths and weaknesses among the poor readers in word recognition and listening comprehension in second grade would be foreshadowed by their performance in kindergarten. Specifically, poor readers who had deficits in listening comprehension in second grade were expected to have performed poorly in listening comprehension in kindergarten. Moreover, children with poor word recognition in second grade were ex- 
pected to have scored poorly on kindergarten measures that have been shown to be related to word recognition (i.e., letter identification, phonological processing).

Table 2 indicates that these predictions held true for listening comprehension. As expected, children in the LLD and hyperlexic subgroups performed significantly less well than those in the dyslexic and nonspecified subgroups on kindergarten measures of listening comprehension, $F(3,179)=14.5, p<.001$. However, expected differences were less apparent for variables related to word recognition. Whereas the hyperlexic and nonspecified subgroups had higher mean scores on kindergarten letter identification than did the dyslexic and LLD subgroups, the overall ANOVA failed to reach significance, $F(3,179)=2.1, p=.11$. In the case of kindergarten phonological awareness and rapid naming, it was expected that the hyperlexic and nonspecified subgroups would have outperformed the dyslexic and LLD subgroups. The nonspecified subgroup did perform significantly better than the LLD subgroup $(p<.005)$ but not better than the dyslexic subgroup $(p>.05)$. The hyperlexic subgroup did not significantly outperform the dyslexic and LLD subgroups $(p>.05)$ in either phonological awareness or rapid naming.

Because the latter results were unexpected, we looked at the subgroups' performance on secondgrade measures of phonological awareness and rapid naming (see Table 3). Here again we predicted that the hyperlexic and nonspecified subgroups would perform significantly better than the other subgroups. However, we found that the hyperlexic and nonspecified subgroups performed significantly better on rapid naming than the LLD subgroup $(p<.01)$ but not the dyslexic subgroup $(p>.05)$. In the case of phonological awareness, the nonspecified subgroup scored significantly higher than the dyslexic and LLD subgroups $(p<.001)$, but, again, the hyperlexic subgroup did not differ significantly in the expected way from the dyslexic subgroup $(p>.05)$.

One variable that might help explain the differences in the word recognition abilities of children in

\section{Nonspecified}

$13.4 \%$

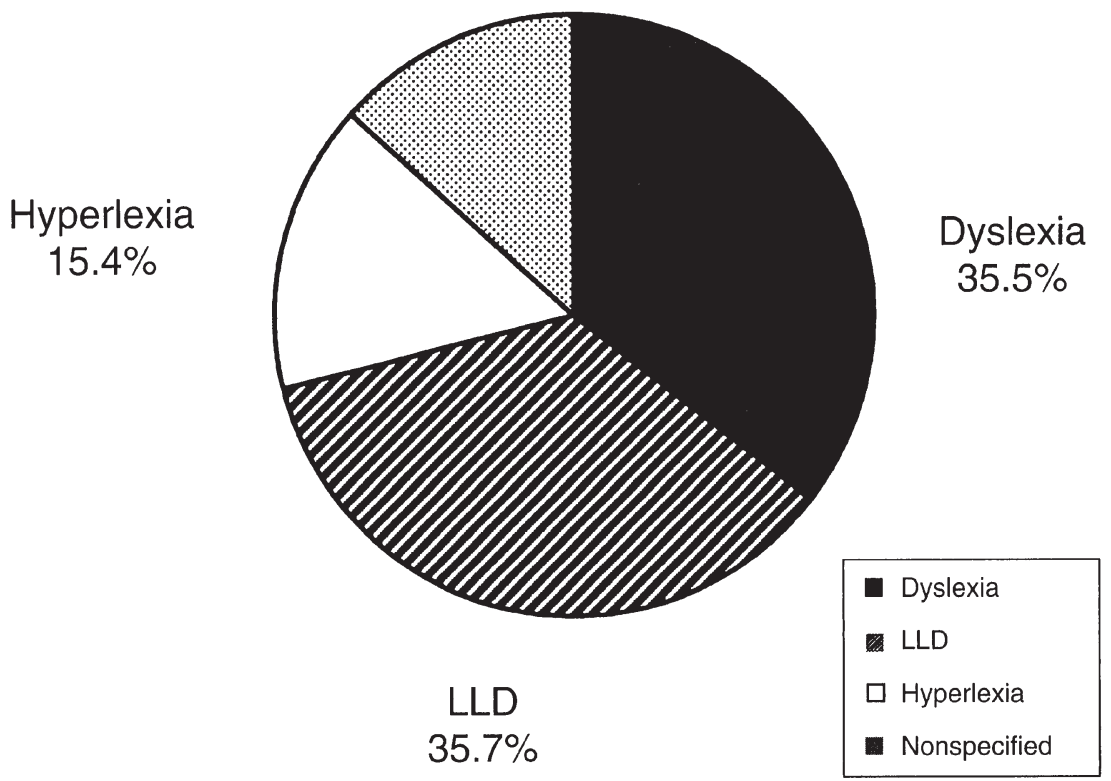

Figure 2. Percentage of children in each of the poor reader subgroups using a cutoff $z$ score of -1 . the dyslexic versus hyperlexic subgroups is reading experience. Increased reading experience among children with hyperlexia could help account for how they scored better in word recognition than the children with dyslexia, despite similarities in phonological processing deficits. The nearly significant difference between these groups in letter identification showed a trend in support of this hypothesis. In addition to the Letter Identification task, we had one further measure of reading experience. This was the Title Recognition task that was administered in the second grade. On this task, children in the hyperlexic subgroup outperformed those in the dyslexic subgroup (see Table 3). In fact, the hyperlexic subgroup performed well within the average range and significantly better than all other subgroups on this task, $F(3,179)=3.0, p<.05$.

\section{Subgroup Stability}

We also examined poor readers' performance in word recognition, listening comprehension, and reading comprehension in the fourth grade. The results indicated that children's abilities in these areas were relatively consistent from second to fourth grade. Pearson product-moment correlation coefficients between second and fourth grade word recognition, listening comprehension, and reading comprehension were $.77, .82$, and .70 , respectively.

Table 4 further shows that poor reader subgroups (based on secondgrade performance) continued to be differentiated on the basis of word recognition and listening comprehension in fourth grade. Children with dyslexia and LLD profiles in second grade maintained their deficits in word recognition compared to children in the hyperlexic and nonspecified subgroups, $F(3,162)$ $=29.1, p<.001$. Furthermore, children with LLD and hyperlexic profiles continued to perform less well in listening comprehension compared to those in the dyslexic and nonspecified subgroups, $F(3,162)$ $=35.0, p<.001$. For the most part, 
Table 1. Performance on Second-Grade Measures by Subgroup

\begin{tabular}{lcccccrrr}
\hline & \multicolumn{2}{c}{ Dyslexic } & \multicolumn{2}{c}{ LLD } & \multicolumn{2}{c}{ Hyperlexic } & \multicolumn{2}{c}{ Nonspecified } \\
Measure & M & SD & M & SD & M & SD & M & SD \\
\hline Word recognition & $75.0_{\mathrm{a}}$ & 6.5 & $72.7_{\mathrm{a}}$ & 6.6 & $91.9_{\mathrm{b}}$ & 3.6 & $93.5_{\mathrm{b}}$ & 5.0 \\
Listening comprehension & $95.1_{\mathrm{a}}$ & 6.2 & $72.6_{\mathrm{b}}$ & 6.6 & $75.1_{\mathrm{b}}$ & 4.9 & $92.3_{\mathrm{a}}$ & 4.3 \\
Reading comprehension & $76.3_{\mathrm{a}}$ & 6.4 & $72.8_{\mathrm{b}}$ & 6.2 & $81.1_{\mathrm{c}}$ & 1.9 & $81.1_{\mathrm{c}}$ & 2.0 \\
Nonverbal IQ & $92.7_{\mathrm{a}}$ & 10.1 & $79.4_{\mathrm{b}}$ & 9.3 & $83.0_{\mathrm{b}}$ & 6.1 & $96.6_{\mathrm{a}}$ & 10.2 \\
\hline
\end{tabular}

For each row, means sharing the same subscripts are not significantly different at $p<.05$.

Table 2. Performance on Kindergarten Measures by Subgroup

\begin{tabular}{|c|c|c|c|c|c|c|c|c|}
\hline \multirow[b]{2}{*}{ Measure } & \multicolumn{2}{|c|}{ Dyslexic } & \multicolumn{2}{|c|}{ LLD } & \multicolumn{2}{|c|}{ Hyperlexic } & \multicolumn{2}{|c|}{ Nonspecified } \\
\hline & M & SD & M & SD & $\mathrm{M}$ & SD & $\mathrm{M}$ & SD \\
\hline Listening comprehension & $88.3_{a}$ & 8.7 & $78.5_{b}$ & 9.5 & $72.5_{b}$ & 7.2 & $90.4_{a}$ & 8.9 \\
\hline Letter identification & $82.2_{\mathrm{a}}$ & 11.4 & $81.9_{\mathrm{a}}$ & 9.0 & $88.9 \mathrm{a}$ & 8.6 & $85.6_{a}$ & 11.8 \\
\hline Phonological awareness & $88.0_{a, c}^{a}$ & 8.3 & $84.2_{\mathrm{b}}^{\mathrm{a}}$ & 5.3 & $84.8_{\mathrm{a}, \mathrm{b}}^{\mathrm{a}}$ & 4.8 & $90.3_{\mathrm{c}}^{\mathrm{a}}$ & 6.7 \\
\hline Rapid naming & $91.0_{\mathrm{a}, \mathrm{b}}^{\mathrm{a}, \mathrm{c}}$ & 12.4 & $81.9_{\mathrm{C}}$ & 11.5 & $84.0_{\mathrm{a}, \mathrm{c}}^{\mathrm{a}, \mathrm{c}}$ & 8.2 & $93.6_{b}$ & 13.3 \\
\hline
\end{tabular}

Subgroups based on second-grade criterion measures. For each row, means sharing the same subscripts are not significantly different at $p<.05$.

Table 3. Performance on Second-Grade Measures Related to Word Recognition by Subgroup

\begin{tabular}{lccccrrrr}
\hline & \multicolumn{2}{c}{ Dyslexic } & \multicolumn{2}{c}{ LLD } & \multicolumn{2}{c}{ Hyperlexic } & \multicolumn{2}{c}{ Nonspecified } \\
Measure & $\mathrm{M}$ & $\mathrm{SD}$ & $\mathrm{M}$ & $\mathrm{SD}$ & $\mathrm{M}$ & $\mathrm{SD}$ & $\mathrm{M}$ & $\mathrm{SD}$ \\
Phonological awareness & $85.2_{\mathrm{a}}$ & 12.1 & $69.8_{\mathrm{b}}$ & 12.4 & $86.6_{\mathrm{a}, \mathrm{c}}$ & 10.8 & $95.0_{\mathrm{c}}$ & 6.8 \\
Rapid naming & $91.7_{\mathrm{a}}$ & 17.8 & $81.1_{\mathrm{b}}$ & 12.2 & $91.4_{\mathrm{a}}$ & 7.2 & $92.8_{\mathrm{a}}$ & 11.4 \\
Title recognition & $88.8_{\mathrm{a}}$ & 14.2 & $93.0_{\mathrm{a}}$ & 13.8 & $101.8_{\mathrm{b}}$ & 10.4 & $90.6_{\mathrm{a}}$ & 17.4 \\
\hline
\end{tabular}

For each row, means sharing the same subscripts are not significantly different at $p<.05$.

Table 4. Performance on Fourth-Grade Measures by Subgroup

\begin{tabular}{|c|c|c|c|c|c|c|c|c|}
\hline \multirow[b]{2}{*}{ Measure } & \multicolumn{2}{|c|}{ Dyslexic } & \multicolumn{2}{|c|}{ LLD } & \multicolumn{2}{|c|}{ Hyperlexic } & \multicolumn{2}{|c|}{ Nonspecified } \\
\hline & M & SD & M & SD & M & $\mathrm{SD}$ & M & SD \\
\hline Word recognition & $74.3 \mathrm{a}$ & 8.7 & $73.7_{\mathrm{a}}$ & 10.6 & $93.4_{b}$ & 6.1 & $93.8_{b}$ & 7.5 \\
\hline Listening comprehension & $94.5_{\mathrm{a}}^{a}$ & 7.3 & $75.8_{\mathrm{b}}^{\mathrm{a}}$ & 10.3 & $74.8_{\mathrm{b}}$ & 6.7 & 93.6 & 7.5 \\
\hline Reading comprehension & $83.9^{\mathrm{a}}$ & 9.5 & $75.1_{b}{ }_{b}$ & 11.2 & $81.7_{\mathrm{a}}^{\mathrm{D}}$ & 5.5 & $91.2_{\mathrm{c}}^{\mathrm{a}}$ & 6.7 \\
\hline
\end{tabular}

Subgroups based on second-grade criterion measures. For each row, means sharing the same subscripts are not significantly different at $p<.05$. 
subgroups maintained their deficits in reading comprehension. The exception was the nonspecified subgroup, which showed a mean reading comprehension composite score within the average range in fourth grade.

Finally, we more directly examined the stability of subgroup classification from second to fourth grade. For this analysis, we reclassified the poor readers identified in second grade into Reading Component subgroups based on their fourth-grade word recognition and listening comprehension scores. As shown in Table 5, subgroup stability was moderately high, with approximately two thirds of the poor readers maintaining their subgroup classification from second to fourth grades. The dyslexic subgroup was very stable, showing a nearly $70 \%$ stability rate. Children in this subgroup who changed categories most often moved into the LLD subgroup (18.1\%). The hyperlexic subgroup showed a similar pattern, with moderately high stability (65\%) and some children moving to the LLD subgroup $(18.5 \%)$.

Subgroup stability was lowest for children with an LLD profile in second grade. Although the majority of these children maintained their original subgroup placement $(54.6 \%)$, many moved into other subgroups. Some of the latter, however, still showed a borderline LLD profile. When borderline cases were included (cutoff criteria changed to the 25 th percentile rather than the 16th),
$71 \%$ of the poor readers in the original LLD subgroup maintained this placement in the fourth grade. A similar procedure that allowed for borderline cases was applied to the classification of poor readers in the dyslexic, hyperlexic, and nonspecified subgroups. The results from this analysis showed a stability rating of $89 \%, 84 \%$, and $92 \%$, respectively.

\section{Discussion}

The results of this investigation indicate that the Reading Component Model is a viable scheme for classifying poor readers. For a classification model to be useful, it should minimally subgroup poor readers on the basis of strengths and weaknesses in independent, reading-related abilities. Our results showed that the two main dimensions of the Reading Component Model--word recognition and listening comprehension--were, for the most part, independent in second-grade poor readers. As such, we found that some poor readers had weaknesses in word recognition and listening comprehension, whereas others had relative strengths in one or the other of these components.

Although poor readers differed in their strengths and weaknesses on these parameters, they did not cluster into homogeneous subgroups. Rather, poor readers were found to have abilities in word recognition and listening comprehension that were continuous and spread

Table 5. Comparison of Subgroup Classification in Second and Fourth Grades

\begin{tabular}{lcccc}
\hline & \multicolumn{4}{c}{ Fourth-grade subgroup } \\
\cline { 2 - 5 } Second-grade subgroup & Dyslexic & LLD & Hyperlexic & Nonspecified \\
\hline Dyslexic & 69.8 & 18.1 & 3.8 & 8.2 \\
LLD & 14.6 & 54.6 & 11.8 & 19.1 \\
Hyperlexic & 2.5 & 18.5 & 65.0 & 14.1 \\
Nonspecified & 20.1 & 0.0 & 9.9 & 70.0 \\
\hline
\end{tabular}

Values represent percentages of second graders that were in each of the specific subgroups in fourth grade. Values in bold represent participants with the same classification in both grades. throughout the two-dimensional space representing these abilities. Such heterogeneity without clustering is consistent with the results of other classification studies that have used continuous rather than categorical criterion variables (Ellis, 1985; Ellis et al., 1996; Murphy \& Pollatsek, 1994).

\section{Subgroup Prevalence}

Because discrete, homogeneous subgroups were not identified, the issue of subgroup prevalence is more relative than absolute. The continuous distributions of word recognition and listening comprehension abilities require subgroup boundaries to be imposed rather than observed. As a result, subgroup prevalence can vary with the choice of cutoff scores for boundaries. We chose to use a rather standard cutoff value of $-1 z$ score to identify subgroups. Accordingly, we observed that poor readers fell into four subgroups, with the majority falling into the dyslexic $(35.5 \%)$ and LLD (35.7\%) subgroups. These subgroups share a deficit in word recognition abilities. Thus, more than $70 \%$ of children who had problems in reading comprehension in second grade had deficits in word recognition. This finding is consistent with previous work that has shown word recognition deficits to play a major role in reading disabilities in the early school grades (e.g., Olson, Kliegl, Davidson, \& Folz, 1985; Rack et al., 1992). Much attention has been given to the underlying causes and treatment of these problems (see Torgesen, 1999). This effort seems justified given the prevalence of word recognition problems in poor readers.

Nevertheless, our results indicate that half of the poor readers with deficits in word recognition also may have significant problems in listening comprehension. Poor readers with the latter profile (i.e., children with LLD) have only recently received attention in research and practice. This work has shown that 
children with LLD may differ from other poor readers (primarily children with dyslexia) in terms of neurological structure/function and, perhaps, speech perceptual abilities (Goulandris et al., 2000; Heath et al., 1999; Joanisse et al., 2000; Leonard, 2001). However, this work is far from conclusive, and more effort is needed to understand the nature of the reading and language problems these children experience.

We also identified a subgroup of children with poor listening comprehension and relatively good word recognition. This hyperlexic subgroup represented approximately $15 \%$ of the poor readers in our sample. Such a rate is consistent with previous estimates of the prevalence of these poor readers (Aaron, 1997; Nation, 1999). Although a portion of poor readers was observed to show this pattern of performance, it should be noted that no child in our hyperlexic subgroup demonstrated an extreme case in which word recognition was well above average and listening and reading comprehension scores were very poor. One poor reader did show an exceptionally high word recognition score $(\mathrm{SS}=118)$ combined with a poor listening comprehension score (SS = 88). However, the latter score was not severe enough to meet the cutoff criterion for the hyperlexic subgroup. Thus, our results suggest that whereas extreme cases of hyperlexia have been observed (Aram et al., 1984; Fontenelle \& Alarcon, 1982), such cases may be rare in a representative sample of poor readers (see Note 4).

A fourth subgroup of poor readers was also observed. Children in this subgroup, referred to as having a non-specified reading disorder, showed scores above the cutoff level in word recognition and listening comprehension despite poor reading comprehension. Although this subgroup was small $(13.2 \%)$, its presence was not predicted by the Reading Component Model. Based on this model, children with relatively good word recognition and listening com- prehension should not have difficulties in reading comprehension. Several factors, however, might account for the presence of these children in the study. First, other variables beyond word recognition and listening comprehension might contribute to reading comprehension deficits, and children in this subgroup could have deficits in these areas.

Second, measurement error combined with the imposition of boundaries in a continuous two-dimensional space may also contribute to the presence of this subgroup. Figure 1 shows that many of the children in this subgroup were near the cutoff values for the other subgroups and actually scored relatively poorly on word recognition or listening comprehension. Because of measurement error, it is likely that at least some of these children's true scores would place them within one of the other subgroups. Finally, it is possible (again because of measurement error) that some of the children in this subgroup were misidentified as poor readers in second grade and that their word recognition and listening comprehension scores were indicative of their true reading comprehension ability. The latter hypothesis gains some support from the observation that when children in the nonspecified subgroup were retested in fourth grade, their mean score in reading comprehension was within the average range.

\section{Subgroup Precursors}

We further hypothesized that the strengths and weaknesses of second-grade poor readers in word recognition and listening comprehension would be foreshadowed by their abilities or disabilities in related variables in kindergarten. This proved to be true in the case of listening comprehension. Poor readers who scored less well in listening comprehension in the second grade (LLD and hyperlexic subgroups) demonstrated similar deficits in listening comprehension in kindergar- ten, whereas those with better listening comprehension in the second grade (dyslexic and nonspecified subgroups) showed somewhat comparable abilities in kindergarten. Although the last two subgroups did not perform as well in listening comprehension in kindergarten as they did in second grade, their kindergarten performance was still significantly better than that of the LLD and hyperlexic subgroups.

Our results for kindergarten variables related to word recognition were less consistent. We expected that poor readers with deficits in word recognition in the second grade (dyslexic and LLD subgroups) would perform poorly on measures of letter identification, phonological awareness, and rapid naming. As noted earlier, each of these measures has been shown to be a precursor of word recognition. Predictions in this regard held true for children in the LLD subgroup. However, the results were mixed for children with a dyslexic profile. Although these children scored poorly in letter identification, their mean performance in phonological awareness and rapid naming was in the low-average range.

Children with a hyperlexic profile also did not perform as expected on kindergarten measures. Because these children had relatively good word recognition abilities in the second grade, we expected that they would have scored within the average range on kindergarten precursors. However, children in the hyperlexic subgroup had performed poorly in phonological awareness and rapid naming at kindergarten testing. Despite their good word recognition, these children's performance on the phonological variables was not significantly different from that of the children in the dyslexic subgroup, who were expected to have phonological deficits. Furthermore, not only were deficits in phonological awareness observed at kindergarten, but they continued to be present into second grade. Although we did not anticipate this pattern, 
others have noted that children with hyperlexia may not score well on measures of phonological awareness (Goldberg \& Rothermel, 1984; Sparks, 1995). Nation (1999), however, raised the possibility that these children's poor performance on phonological awareness tasks may be due to their limited understanding of task demands and may not be a true reflection of their underlying phonological skills.

Nation (1999) further suggested that the relatively good word recognition skills of children with a hyperlexic profile may stem in part from their reading experience or practice. These children may be drawn particularly to print and in some cases are even compulsive about reading. Our results provide some support for the influence of literacy experience on the word recognition skills of these children. In kindergarten, children with a hyperlexic profile were found to have a mean letter identification score in the low-average range. As noted in the method section, it is likely that children's performance on the Letter Identification task was influenced in part by their reading experience. Moreover, children in the hyperlexic subgroup performed well within the average range on the Title Recognition task. This task measured children's knowledge of the titles of well-known children's books. Although it was given in the second grade, the good performance of the hyperlexic subgroup was likely a reflection of at least several years of literacy experience.

\section{Subgroup Stability}

We also examined the stability of poor readers' performances related to the Reading Component Model. Children identified as poor readers in the second grade were retested in the fourth grade. Our results demonstrated that poor readers were consistent in their performances on measures of word recognition and listening comprehension. High correlations were found on these measures between second and fourth grades. Stability was also seen in re- gard to subgrouping. Subgroups identified in the second grade continued to show the same pattern of significant differences on readingrelated variables in the fourth grade (see Table 4) as was seen in second grade (see Table 1). Finally, when poor readers were reclassified based on fourth-grade measures of word recognition and listening comprehension, their subgroup placement was generally consistent with the original classification. Overall, 64.6\% of the poor readers maintained the same subgroup placement they had shown in the second grade.

This stability rate seems acceptable given the numerous factors that might affect classification stability in a study such as this. For example, regression to the mean, the tendency for extreme scores to regress back toward the mean, is a factor that is likely to cause some instability. Specifically, such an effect could have a particular influence on children in the LLD subgroup. Because the LLD classification required poor performance on two dimensions, some children originally in this subgroup would be expected to show scores that regressed to the mean on one or the other of the dimensions. As noted earlier, this group did show the greatest instability from second to fourth grade. Although regression to the mean no doubt accounted for some of this variability, the data from the other subgroups suggested that other factors were operative as well. Specifically, children with a dyslexic or hyperlexic profile in the second grade were more likely to be reclassified as having LLD in the fourth grade than to regress in their word recognition scores or listening comprehension scores and be classified as having a nonspecified reading problem. Thus, with the exception of the LLD subgroup (which precluded a shift to a subgroup with more extreme impairment), more poor readers moved downward in classification than moved upward.

The effects of measurement error, including regression to the mean, were magnified in our classification system because the group- ing decisions involving each dimension were dichotomous. Specifically, at least some participants on the border between subgroups would be expected to make small changes in scores and shift subgroups from second- to fourth-grade testing. An expansion of the category boundaries might capture this variability and improve our estimate of subgroup stability. Indeed, we showed that when our definition of a deficit in fourth grade was expanded to include cases on the border, the overall classification stability improved from $64.6 \%$ to $82.8 \%$.

Finally, intervention between second and fourth grade might account for some inconsistency in classification. Not only could intervention lead to improved reading comprehension, but it could positively affect both word recognition and listening comprehension. Unfortunately, data concerning the intervention history of our participants were unavailable. However, future investigations of the Reading Component Model might take intervention history into consideration.

\section{Matthew Effects}

One argument against the use of the IQ-achievement discrepancy model is the possibility not only that IQ influences reading but that reading affects IQ (Siegel, 1989; Stanovich, 1991). This type of reciprocal causation involving reading and other cognitive abilities has been labeled the Matthew effect (Stanovich, 1986). One possible result of this effect is that over time, the lack of reading experience by poor readers leads to a decrease in their IQ scores. Indeed, some studies have provided support for such lowering of IQ scores over time in poor readers (Bishop \& Butterworth, 1980; van Den Bos, 1988). The Matthew effect is relevant to classifying children with reading disabilities because the depression of IQ scores over time may result in fewer poor readers showing a discrepancy between reading achievement and IQ (i.e., fewer children with specific reading disability). 
Stanovich (1991) has suggested that although listening comprehension has advantages over IQ as a classification variable, it may be especially vulnerable to the Matthew effect. The longitudinal nature of the present study provided an opportunity to examine a possible Matthew effect on listening comprehension. In general, however, our results failed to find evidence of this effect. Poor readers' scores in listening comprehension remained fairly stable from kindergarten to fourth grade. Few notable differences were observed in the mean listening comprehension scores for any given subgroup over this time period. Where relevant differences were observed, they were between kindergarten and second grade (see LLD subgroup) and not between second and fourth grade, where the Matthew effect should have been even stronger. Also, if the Matthew effect had been present (and the listening comprehension score had gone down over time in poor readers), we would have expected that in fourth grade, fewer poor readers would have been classified as having dyslexia and more as having LLD or hyperlexia than were so classified in second grade. Our results did not show this to be the case. Thus, our data indicate that at least through the fourth grade, the Matthew effect may have a limited influence on listening comprehension and may not be a serious obstacle to the use of the Reading Component Model to classify poor readers.

\section{Clinical Implications}

An important strength of the Reading Component Model is that it has implications for intervention. As noted earlier, the IQ-achievement discrepancy approach provides little direction for the assessment and treatment of reading disabilities (Aaron, 1997; Catts \& Kamhi, 1999). The Reading Component Model, on the other hand, has the advantage of identifying strengths and weaknesses in components critical to reading development. As such, it al lows the proximal cause of reading problems to be identified and the appropriate set of intervention strategies to be put in place.

First, the Reading Component Model minimally suggests that the assessment of reading disabilities should routinely include the measurement of word recognition, listening comprehension, and related abilities. The specific assessment instruments may vary with age or with the severity of the reading disability. In some cases, the instruments used in the present investigation will be appropriate for initial evaluations. In other situations, different instruments could be employed. For example, the listening comprehension subtest from standardized tests such as the Woodcock Language Proficiency Battery-Revised (Woodcock, 1991) or the Wechsler Individual Achievement Test (Wechsler, 1992) or a similar subtest from a criterion-referenced measure such as the Qualitative Reading Inventory-3 (Leslie \& Caldwell, 2001) can be used with individuals across a wide age range. Moreover, in the case of word recognition, it may be necessary to go beyond measures of accuracy to those tapping reading speed or fluency (e.g., Torgesen, Wagner, \& Rashotte, 1997). In the Reading Component Model presented here, we do not directly consider word recognition speed. Recent research, however, has suggested that poor readers may vary in their decoding speed and that this aspect of reading may need to be considered in addition to word recognition accuracy. Aaron et al. (1999), for example, identified several poor readers who had problems in word reading speed but not in word recognition accuracy or listening comprehension (see Note 5). These findings and their clinical implications could easily be accounted for by expanding the Reading Component Model to include a reading speed component (see Catts \& Kamhi, 1999). Other dimensions of word recognition (e.g., orthographic or morphemic processing) might also be added and considered in assessment. Finally, listening comprehension could be broken down into subcomponents (e.g., vocabulary and grammatical processing, inference making), as was partially done in the present study, and each of these components could be assessed.

The results of an assessment based on the Reading Component Model also should have direct implications for treatment. This model shifts the focus away from assumptions of inherent abilities or potential often associated with IQ testing and places it on individual differences in skills that are amenable to instruction. By identifying strengths and weaknesses in components involved in skilled reading, the Reading Component Model can provide guidance for selecting the most appropriate intervention strategies for a given poor reader. In some cases, poor readers will demonstrate reading component profiles that involve a clear dissociation between word recognition and listening comprehension abilities. For example, some children will have very poor word recognition in the face of good or adequate listening comprehension (i.e., a strong dyslexic profile). These children should receive intervention focused on improving their word decoding and related abilities (e.g., phonological awareness). Current research has documented that such an intervention can significantly reduce the word reading difficulties experienced by many of these children (Torgesen, 1999).

In other instances, children may have significant deficits in listening comprehension combined with good or at least adequate word recognition (i.e., a strong hyperlexic profile). For these children, intervention should focus on their comprehension problems. This may include activities to improve vocabulary, grammatical understanding, and text-level processing, as well as metacognitive strategies to aid comprehension (Simmons \& Kameenui, 1998; Westby 1999). Research has shown that such intervention can have a significant impact on comprehension (Baker, Simmons, \& Kameenui, 1998; Swanson, Carson, \& Sachse-Lee, 1996). 
For other poor readers, deficits may be observed in both word recognition and listening comprehension. The extreme case of this would be a child with a strong LLD profile. As reported earlier, these children have often not qualified for special reading programs and have received treatment, if at all, through different mechanisms. However, research has shown that these children can benefit from intervention and, in the case of word recognition intervention, perhaps even to the same extent as children with a dyslexic profile (Hatcher \& Hulme, 1999; RainingBird, Cleave, \& McConnell, 2001; Torgesen, Wagner, et al., 1999; Vellutino, Scanlon, \& Lyon, 2000).

Finally, other poor readers will have borderline deficits in either word recognition or listening comprehension, or in both. Although these children may be classified in one or the other of the subgroups, the presence of borderline deficits suggests that intervention needs to target the deficit area(s). The important point here is that whereas the Reading Component Model can be useful in designing intervention for prototypical cases of each of the subgroups, it can also be helpful in identifying borderline problems and in planning intervention for these problems. As the Reading Component Model is expanded to include other components, it should be useful in highlighting both significant and borderline deficits in other aspects of reading.

\section{Acknowledgments}

This study was supported by a grant from the National Institute of Deafness and Other Communication Disorders ( 1-P50-DC02726-04). The authors would like to thank J. Bruce Tomblin and his research team including Xuyang Zhang, Paula Buckwalter, Marlea O'Brien, Connie Ferguson, Jodi Schwartz, and Amy Kundel for their valuable contributions to this investigation.

\section{D $\mathbf{0} \quad \mathbf{0} \quad \mathbf{0} \quad \mathbf{0}$}

Hugh W. Catts, PhD, is a professor of speech-language-hearing at the University of Kansas. His primary interests include developmental language and reading disabilities. Address: Hugh W. Catts, University of Kansas, Department of SpeechLanguage-Hearing, 1000 Sunnyside Ave., Lawrence, KS 66045.

Tiffany P. Hogan, MS, is a doctoral student in the Department of Speech-Language-Hearing at the University of Kansas. She is interested in speech and language disorders and their connection to reading disabilities.

Marc E. Fey, PhD, is a professor of hearing and speech at the University of Kansas Medical Center. His primary interests include the identification and treatment of oral and written language disorders.

\section{Notes}

1. Only unweighted data can be displayed in a scatter plot such as the one shown in Figure 1. However, the pattern of results seen in this figure does not deviate significantly from what might be expected in a weighted analysis. In fact, the Pearson product-moment correlation coefficient for the unweighted data $(r=.18)$ is essentially the same as for the weighted data. The primary difference in a weighted analysis is that the individual data points are given different weights. This of course means that one cannot derive the prevalence of poor readers in each subgroup by counting data points in each quadrant of Figure 1.

2. Again, it should be noted that the term hyperlexic is used by some to refer to a group of children who not only show this reading component profile but also have autism or other developmental disabilities. To distinguish the latter group of children from the more general group used in our model, the reader should read the term hyperlexic as hyperlexic-like. We have chosen to retain the term hyperlexic in the text for ease of presentation. A similar approach is also appropriate for the term dyslexic. When referring to children with this profile, the term should be read as dyslexic-like to distinguish the current usage of the term from the many ways that it has been used in the literature.

3. As noted, the prevalence of subgroups will vary with the cutoff value chosen. For example, if -.75 had been used as a cutoff, the LLD subgroup would have been larger $(48.6 \%)$ and the dys- lexic, hyperlexic, and nonspecified subgroups would have been smaller $(30.9 \%, 10.8 \%$, and $9.7 \%$, respectively). If the cutoff were set at -1.25 , there would have been more poor readers in the nonspecified subgroup (30.1\%) and fewer in the dyslexic (31.4\%)and LLD $(22.1 \%)$ subgroups. The hyperlexic subgroup would have had about the same prevalence $(16.3 \%)$.

4. The lack of extreme cases of hyperlexia in our sample may have been influenced in part by our participant selection criteria. In the epidemiologic study in which our sample originally participated, children with autism or mental retardation were excluded. Some studies have reported that extreme cases of hyperlexia often coexist with these developmental disorders (Healy, Aram, Horwitz, \& Kessler, 1982); thus, such cases would have been missed in our study.

5. Although Aaron et al. (1999) identified these poor readers in third grade, further analyses from their study showed that a reading speed factor did not clearly emerge until sixth grade. Joshi and Aaron (2000), however, have shown that a measure of letter naming speed added unique variance to measures of word attack and listening comprehension in predicting reading comprehension in a small sample of third-grade children.

\section{References}

Aaron, P. G. (1991). Can reading disabilities be diagnosed without using intelligence tests? Journal of Learning Disabilities, 24, 178-186, 191.

Aaron, P. G. (1997). The impending demise of the discrepancy formula. Review of Educational Research, 67, 461502.

Aaron, P. G., Frantz, S. S., \& Manges, A. R. (1990). Dissociation between pronunciation and comprehension in reading disabilities. Reading and Writing: An Interdisciplinary Journal, 3, 1-22.

Aaron, P. G., Joshi, M., \& Williams, K. A. (1999). Not all reading disabilities are alike. Journal of Learning Disabilities, 32, 120-137.

Aram, D. M., Rose, D. E, \& Horwitz, S. J. (1984). Hyperlexia: Developmental reading without meaning. In R. N. Malatesha \& H. A. Whitaker (Eds.), Dyslexia: A global issue (pp. 517-531). The Hague: Martinus Nijhoff.

Badian, N., McAnulty, G., Duffy, G., \& Als, H. S. (1990). Prediction of dyslexia in kindergarten boys. Annals of Dyslexia, 40, 152-167. 
Baker, S. K., Simmons, D. C., \& Kameenui, E. J. (1998). Vocabulary acquisition: Instructional and curricular basics and implications. In D. C. Simmons \& E. J. Kameenui (Eds.), What reading research tells us about children with diverse learning needs (pp. 219-238). Mahwah, NJ: Erlbaum.

Bishop, D. V. M., \& Adams, C. (1990). A prospective study of the relationship between specific language impairment, phonological disorders, and reading retardation. Journal of Child Psychology and Psychiatry, 31, 1027-1050.

Bishop, D. V. M., \& Butterworth, G. E. (1980). Verbal-performance discrepancies: Relationship to birth risk and specific reading retardation. Cortex, $16,375-390$.

Bruck, M. (1988). The word recognition and spelling of dyslexic children. Reading Research Quarterly, 23, 51-69.

Catts, H. W., \& Kamhi, A. G. (Eds.). (1999). Language and reading disabilities. Needham Heights, MA: Allyn \& Bacon.

Catts, H. W., Fey, M. E., Zhang, X., \& Tomblin, J. B. (1999). Language basis of reading and reading disabilities: Evidence from a longitudinal investigation. Scientific Studies of Reading, 3, 331-361.

Catts, H. W., Fey, M. E., Zhang, X., \& Tomblin, J. B. (2001). Estimating the risk of future reading difficulties in kindergarten children: A research-based model and its clinical implication. Language, Speech, and Hearing Services in Schools, 32, 38-50.

Carver, R. P. (1998). Predicting reading level in Grades 1 to 6 from listening level and decoding level: Testing theory relevant to simple view of reading. Reading and Writing: An Interdisciplinary Journal, 10, 121-154.

Culatta, B., Page, J., \& Ellis, J. (1983). Story retelling as a communicative performance screening tool. Language, Speech, and Hearing Services in Schools, 14, 471-479.

Cunningham, A. E., \& Stanovich, K. E. (1990). Assessing print exposure and orthographic processing skill in children: A quick measure of reading experience. Journal of Educational Psychology, 82, 733-740.

Curtis, M. (1980). Development of the components of reading skill. Journal of Educational Psychology, 72, 656-669.

De Jong, P. F., \& Van der Leij, A. (2002). Effects of phonological abilities and linguistic comprehension on the development of reading. Scientific Studies of Reading, 6, 51-77.
Dunn, L., \& Dunn, L. (1981). Peabody picture vocabulary test-Revised. Circle Pines, MN: American Guidance Service.

Elliott, D. E., \& Needleman, R. M. (1976). The syndrome of hyperlexia. Brain and Language, 3, 339-349.

Ellis, A. W. (1985). The cognitive neuropsychology of developmental (and acquired) dyslexia: A critical survey. Cognitive Neuropsychology, 2, 196205.

Ellis, A. W., McDougall, S., \& Monk, A. E (1996). Are dyslexics different? II. A comparison between dyslexics, reading age controls, poor readers, and precocious readers. Dyslexia: An International Journal of Practice and Research, 2, 59-68.

Fletcher, J. M., Shaywitz, S. E., Shankweiler, D. P., Katz, L., Liberman, I. Y., Stuebing, K. K., et al. (1994). Cognitive profiles of reading disability: Comparisons of discrepancy and low achievement definitions. Journal of Educational Psychology, 86, 6-23

Fletcher, J. M., Francis, D. J., Shaywitz, S. E., Lyon, G. R., Foorman, B. R., Stuebing, K., et al. (1998). Intelligent testing and the discrepancy model for children with learning disabilities. Learning Disabilities Research \& Practice, 13, 186-203.

Flowers, L., Meyer, M., Lovato, J., Wood, F., \& Felton, R. (2001). Does third grade discrepancy status predict the course of reading development? Annals of Dyslexia, 51, 49-74.

Fontenelle, S., \& Alarcon, M. (1982). Hyperlexia: Precocious word recognition in developmentally delayed children. Perceptual and Motor Skills, 55, 247252.

Forness, S. R., Sinclair, E., \& Guthrie, D. (1983). Learning discrepancy formulas: Their use in actual practice. Learning Disability Quarterly, 6, 107-114.

Goldberg, T., \& Rothermel, R. (1984). Hyperlexic children reading. Brain, 107, 759-785.

Gough, P. B., \& Tunmer, W. E. (1986). Decoding, reading, and reading disability. Remedial and Special Education, 7(1), 6-10.

Goulandris, N. K., Snowling, M. J., \& Walker, I. (2000). Is dyslexia a form of specific language impairment? A comparison of dyslexic and language impaired children as adolescents. Annals of Dyslexia, 50, 103-120.

Hatcher, P. J., \& Hulme, C. (1999). Phonemes, rhymes, and intelligence as predictors of children's responsiveness to remedial reading instruction:
Evidence from a longitudinal intervention study. Journal of Experimental Child Psychology, 72, 130-153.

Healy, J. M., Aram, D. M, Horwitz, S. J., \& Kessler, J. W. (1982). A study of hyperlexia. Brain and Language, 17, 1-23.

Heath, S. M., Hogben, J. H., \& Clark, C. D. (1999). Auditory temporal processing in disabled readers with and without oral language delay. Journal of Child Psychology and Psychiatry, 40, 637647.

Hoover, W. A., \& Gough, P. B. (1990). The simple view of reading. Reading and Writing: An Interdisciplinary Journal, 2, 127160 .

Hurford, D. P., Schauf, J. D., Bunce, L., Blaich, T., \& Moore, K. (1994). Early identification of children at risk for reading disabilities. Journal of Learning Disabilities, 27, 371-382.

Jackson, M. D., \& McClelland, J. L. (1979). Processing determinants of reading speed. Journal of Experimental Psychology, 108, 151-181.

Joanisse, M. F., Mannis, F. R., Keating, P., \& Seidenberg, M. S. (2000). Language deficits in dyslexic children: Speech perception, phonology, and morphology. Journal of Experimental Child Psychology, 77, 30-60.

Joshi, R. M., \& Aaron, P. G. (2000). The component model of reading: Simple view of reading made a little more complex. Reading Psychology, 21, 85-97.

Leonard, C. M. (2001). Imaging brain structure in children: Differentiating language disability and reading disability. Learning Disability Quarterly, 24, 158-176.

Leslie, L., \& Caldwell, J. (2001). Qualitative Reading Inventory-3. New York: Addison Wesley Longman.

LoBello, S. G. (1991). A short form of the Wechsler Preschool and Primary Scale of Intelligence-Revised. Journal of School Psychology, 29, 229-236.

Lombardino, L., Leonard, C., \& Eckert, M. (2001, November). Language-learning disability and developmental dyslexia: Evidence for distinct disorders. Poster session presented at the annual meeting of the American Speech-Language-Hearing Association, New Orleans, LA.

Meyer, M. S., Wood, F. B., Hart, L. A., \& Felton, R. H. (1998). Longitudinal course of rapid naming in disabled and nondisabled readers. Annals of Dylexia, 43, 91-114.

Murphy, L., \& Pollatsek, A. (1994). Developmental dyslexia: Heterogeneity without discrete subgroups. Annals of Dyslexia, 44, 120-146. 
Nation, K. (1999). Reading skills in hyperlexia: A developmental perspective. Psychological Bulletin, 125, 338-355.

Newcomer, P. (1990). Diagnostic achievement battery-2. Austin, TX: PRO-ED.

Newcomer, P., \& Hammill, D. (1988). Test of language development-2: Primary. Austin, TX: PRO-ED.

Olson, R. K., Kliegl, R., Davidson, B. J., \& Folz, G. (1985). Individual and developmental differences in reading disability. In C. E. MacKinnon \& T. G. Waller (Eds.), Reading research: Advances in theory and practice (Vol. 4, pp. 1-64). New York: Academic Press.

Palmer, J., McCleod, C., Hunt, E., \& Davidson, J. (1985). Information processing correlates of reading. Journal of Memory and Language, 24, 59-88.

Pennington, B. F., Gilger, J., Olson, R. K., \& DeFries, J. C. (1992). The external validity of age- versus IQ-discrepancy definitions of reading disability: Lessons from a twin study. Journal of Learning Disabilities, 25, 562-573.

Rack, J. P., Snowling, M. J., \& Olson, R. K. (1992). The nonword reading deficit in developmental dyslexia: A review. Reading Research Quarterly, 27, 28-53.

Raining-Bird, K. E., Cleave, P. L., \& McConnell, L. (2001). Reading and phonological awareness in children with Down syndrome: A longitudinal study. American Journal of SpeechLanguage Pathology, 9, 319-330.

Rosner, J., \& Simon, D. (1971). The Auditory Analysis Test: An initial report. Journal of Learning Disabilities, 4, 40-48.

Savage, R. (2001). The simple view of reading: Some evidence and possible implications. Educational Psychology, 17, 17-33.

Semel, E., Wiig, E. H., \& Secord, W. A. (1995) Clinical evaluation of language fundamentals-3. San Antonio, TX: Psychological Corp.

Siegel, L. S. (1989). IQ is irrelevant to the definition of learning disabilities. Journal of Learning Disabilities, 22, 469-478.

Silberberg, N. E., \& Silberberg, M. C. (1967). Hyperlexia: Specific word recognition skills in young children. Exceptional Children, 34, 41-42.

Simmons, D. C., \& Kameenui, E. J. (1998). What reading research tells us about children with diverse learning needs. Mahwah, NJ: Erlbaum.

Sparks, R. L. (1995). Phonemic awareness in hyperlexic children. Reading and Writing: An Interdisciplinary Journal, 7, 217-235.

Stanovich, K. E. (1986). Matthew effects in reading: Some consequences of individual differences in the acquisition of literacy. Reading Research Quarterly, 21, 360-406.

Stanovich, K. E. (1991). Discrepancy definitions of reading disability: Has intelligence led us astray? Reading Research Quarterly, 26, 7-29.

Stanovich, K. E., \& Siegel, L. S. (1994). The phenotypic performance profile of reading-disabled children: A regression-based test of the phonologicalcore variable-difference model. Journal of Educational Psychology, 86, 24-53.

Stanovich, K. E., \& West, R. F. (1989). Exposure to print and orthographic processing. Reading Research Quarterly, 24, 402-433.

Stothard, S. (1994). The nature and treatment of reading comprehension difficulties in children. In C. Hulme \& M. Snowling (Eds.), Reading development and dyslexia (pp. 200-238). London: Whurr.

Stothard, S. E., \& Hulme, C. (1992). Reading comprehension difficulties in children: The role of language comprehension and working memory skills. Reading and Writing, 4, 245-256.

Swanson, H. L., Carson, C., \& Sachse-Lee, C. M. (1996). A selective synthesis of intervention research for students with learning disabilities. School Psychology Review, 25, 370-391.

Tomblin, J. B. (1995). Midwest collaboration on specific language impairment. Bethesda, MD: National Institute of Deafness and Other Communication Disorders.

Tomblin, J. B., Records, N., Buckwalter, P., Zhang, X., Smith, E., \& O'Brien, M. (1997). Prevalence of specific language impairment in kindergarten children. Journal of Speech, Language, and Hearing Research, 40, 1245-1260.

Torgesen, J. K. (1999). Assessment and instruction for phonemic awareness and word recognition skills. In H. W. Catts
\& A. G. Kamhi (Eds.), Language and reading disabilities (pp. 128-153). Needham Heights, MA: Allyn \& Bacon.

Torgesen, J. K., Wagner, R. K., Rashotte, C. A., Lindamood, P., Rose, E., Conway, T., et al. (1999). Preventing reading failure in young children with phonological processing disabilities: Group and individual responses to instruction. Journal of Educational Psychology, 91, 579-593.

Torgesen, J. K., Wagner, R. K., \& Rashotte, C. A. (1997). Test of word reading efficiency. Austin, TX: PRO-ED.

Van Den Bos, K. (1988). Relationship between cognitive development, decoding skill, and reading comprehension in learning disabled Dutch children. In P. G.

Aaron \& R. N. Joshi (Eds.), Reading and writing disorders in different orthographic systems. Dordrecht, The Netherlands: Kluwer.

Vellutino, F. R., Scanlon, D. M., \& Lyon, G. R. (2000). Differentiating between difficult-to-remediate and readily remediated poor readers: More evidence against the IQ-achievement discrepancy definition of reading disability. Journal of Learning Disabilities ,33, 223-238.

Wechsler, D. (1989). Wechsler preschool and primary scale of intelligence-Revised. New York: Psychological Corp.

Wechsler, D. (1991). Wechsler intelligence scale for children-III. San Antonio, TX: Psychological Corp.

Wechsler, D. (1992). Wechsler individual achievement test. San Antonio, TX: Psychological Corp.

Westby, C. E. (1999). Assessing and facilitating text comprehension problems. In H. W. Catts \& A. G. Kamhi (Eds.), Language and reading disabilities (pp. 154-223). Needham Heights, MA: Allyn \& Bacon.

Wiederholt, J., \& Bryant, B. (1992). Gray oral reading test-3. Austin, TX: PROED.

Woodcock, R. (1987). Woodcock reading mastery tests-Revised. Circle Pines, MN: American Guidance Service.

Woodcock, R. (1991). Woodcock language proficiency battery-Revised. Chicago: Riverside. 